\title{
O programa Bolsa Família Evolução e efeitos sobre a pobreza ${ }^{1}$
}

\author{
Sonia Rocha ${ }^{2}$
}

\section{Resumo}

Depois de um breve retrospecto da evolução das transferências de renda focalizadas nos pobres no Brasil, este artigo analisa a evolução recente do programa Bolsa Família no que diz respeito à focalização e cobertura da sua população alvo, utilizando informações do suplemento das PNADs 2004 e 2006. Apesar de o programa ter atingido sua meta de atendimento de 11 milhões de domicílios ao final de 2006, há evidências de que cerca de 3,4 milhões de domicílios elegíveis ainda se encontram a descoberto. Simulações evidenciam que garantir a cobertura de todos os domicílios elegíveis tem maior impacto sobre os indicadores de pobreza que conceder o novo benefício, criado em 2008, aos jovens nos domicílios já atendidos pelo programa.

Palavras-chave: Política social; Rendimento; Bolsa Família; Transferência de renda; Pobreza.

\begin{abstract}
The Brazilian Bolsa-Familia Program. Evolution and impacts on poverty

After a brief retrospective of the evolution of income transfer programs in Brazil, this article uses information from the 2004 and 2006 official national household survey (PNAD) in order to analyze the recent evolution of the Bolsa Familia program regarding targeting and coverage. Despite the fact that the BF met its goal of assisting 11 million households by the end of 2006, still around 3.4 million eligible households do not receive the transfer benefit. Simulations show that guaranteeing the basic income transfer to all eligible households has a stronger impact on poverty indicators than to grant the new benefit - created in 2008 - to youngsters who live in the already assisted households.
\end{abstract}

Keywords: Social policy; Income; Income transfer; Poverty.

JEL I32.

\section{Introdução}

Em dezembro de 2006, o programa Bolsa Família (BF) atingiu a meta de cobertura da sua população alvo estabelecida pelo Governo, consolidando-se como o carro-chefe da política social do governo Lula. Nos três anos desde a sua criação, em outubro de 2003, foi realizado um esforço importante no sentido de unificar o conjunto de programas preexistentes de transferência de renda focalizados nos pobres, criados a partir dos meados da década de noventa, empreendendo a revisão cadastral das famílias e eliminando superposições dos diferentes programas de transferência que podem ser caracterizados como "novos".

(1) Trabalho recebido em janeiro de 2009 e aprovado em dezembro de 2009.

(2) Economista / Pesquisadora do Instituto de Estudos do Trabalho e Sociedade (IETS), Rio de Janeiro, RJ, Brasil. E-mail: srocha@iets.org.br.

$$
\text { Economia e Sociedade, Campinas, v. 20, n. } 1 \text { (41), p. 113-139, abr. } 2011 .
$$


A experiência brasileira com o programa BF vem adquirindo crescente visibilidade internacional, suscitando o interesse de especialistas em política social, por diversas razões. A primeira são seus números impressionantes, já que estaria concedendo de forma regular cerca de 11 milhões de benefícios mensais, cobrindo, portanto, 19,4\% do total de domicílios brasileiros em 2007. No entanto, estes números seriam certamente um passivo para o programa caso ele não reunisse uma série de características atraentes de concepção e de operacionalização e, sobretudo, se não tivesse ficado evidente o seu sucesso em termos de focalização: com dispêndio relativamente modesto, que não chega a $1 \%$ do PIB, foi possível atingir rapidamente resultados significativos de redução da pobreza e da desigualdade de renda. Estudos mostraram que as transferências realizadas em 2004 foram capazes de reduzir a proporção de pobres, embora este não seja o indicador mais sensível às transferências. Paralelamente, $20 \%$ da queda da desigualdade de renda, medida pelo coeficiente de Gini entre 2001 e 2004, se deveram exclusivamente às novas transferências (Soares, 2006).

A respeitabilidade do programa deve-se, em grande parte, ao fato de que seus impactos puderam ser empiricamente avaliados a partir da Pesquisa Nacional por Amostra de Domicílios - PNAD/IBGE. Trata-se, portanto, de evidências independentes das informações administrativas oriundas do Ministério do Desenvolvimento Social e Combate à Fome (MDS), responsável direto pelo programa, embora o próprio ministério tenha empreendido uma avaliação específica (CEDEPLAR, 2006). Assim, em 2004, cerca de um ano após a criação do BF e ainda em pleno processo de unificação dos programas preexistentes sob este novo "guarda-chuva", foi aplicado um questionário suplementar à totalidade dos 145 mil domicílios da amostra investigada pela PNAD naquele ano. O questionário indagava sobre a participação do domicílio em sete programas específicos de transferência de renda federais em operação naquele momento, além de um quesito aberto sobre a participação em "outros" programas. ${ }^{3}$

Embora houvesse incompatibilidade entre o número de beneficiários por programa advindo dos registros administrativos e aquele derivado da PNAD 2004 (Rocha, 2008a; Soares et al., 2006), as características dos domicílios que declararam receber transferências evidenciaram uma focalização relativamente boa. Pode-se dizer mesmo que a focalização revelou-se surpreendentemente adequada, tendo em vista o fato de que a seleção dos beneficiários do programa foi realizada localmente, isto é, de forma descentralizada, a partir de metas definidas pelo MDS quanto ao número de domicílios a serem atendidos em cada município.

(3) Os programas federais investigados incluíam tanto os "novos" programas federais criados a partir de meados da década de noventa (Programa de Erradicação do Trabalho Infantil, Bolsa Escola, Bolsa Alimentação, Auxílio Gás, Cartão Alimentação, Bolsa Família), assim como os programas constitucionais preexistentes (Benefício de Prestação Continuada a idosos e deficientes) 
Embora esta cooperação entre governo federal e governos municipais para o cadastramento e seleção dos beneficiários tenha sido adotada desde o início de implantação dos "novos" programas de transferência, em meados dos anos noventa, este não é um procedimento sem risco, tendo em vista a ausência de uma rede de assistência social estruturada aliada à tradição clientelista local.

Passados dois anos após a aplicação do primeiro questionário suplementar, a PNAD 2006 incorporou um novo suplemento sobre os programas de transferência de renda. O objetivo deste texto é, fazendo referência aos resultados obtidos em 2004, avaliar em que medida e em que direção avançaram as "novas" transferências no momento em que o governo considerou estarem praticamente finalizados os processos de expansão de cobertura e de unificação sob o BF dos programas de transferência de renda preexistentes. Ademais, utilizando os dados de 2006, são feitas simulações de forma a examinar o impacto provável sobre os indicadores de pobreza da cobertura completa da população alvo do programa, assim como de modificações introduzidas no desenho do programa em 2008, a saber, o pagamento de um auxílio aos jovens de 16 e 17 anos nos domicílios atendidos.

Este texto está organizado da seguinte maneira. Depois de um breve histórico, na próxima seção, sobre a evolução dos programas de transferência de renda no Brasil, a seção 2 discute a expansão da cobertura Bolsa Família e o processo de unificação dos vários programas de transferência de renda preexistentes, que atendiam a clientelas específicas no conjunto mais amplo dos pobres. Discute-se ainda a questão da focalização e do tamanho da população alvo ainda não coberta pelo programa, dando ênfase especial à evolução ocorrida entre 2004 e 2006. A seção 3 descreve os possíveis impactos sobre a pobreza da imputação do benefício do $\mathrm{BF}$ aos domicílios que, embora elegíveis, ainda não recebiam transferência de renda do programa. São feitas também simulações relativas ao novo benefício destinado aos jovens de 16 e 17 anos, que começou a ser pago em março de 2008. Finalmente, sintetiza-se os pontos levantados ao longo do texto e as conclusões.

\section{Da criação e expansão dos programas federais de transferência de renda}

Ao tratar do BF e dos programas preexistentes que ele incorpora, criados desde 1995, é importante destacar que transferências de renda focalizadas nos mais pobres já existiam no Brasil desde a década de setenta. Tinham, porém, pouca visibilidade, além de cobertura bastante limitada da sua população alvo, isto é, idosos e portadores de deficiência com renda monetária insuficiente para garantirem seus meios de sobrevivência. Somente a partir da Constituição de 1988, e, em particular, a partir da regulamentação da Lei Orgânica da Assistência Social (LOAS), em 1993, este programa de transferência adquire importância 
crescente, tanto em função do aumento paulatino da clientela atendida, como do valor do benefício, que passou a corresponder a um salário mínimo. Ainda hoje este programa se diferencia marcadamente dos "novos" programas criados a partir dos meados da década de noventa, por ter embasamento constitucional e, em consequência, regras bem definidas de fixação e de reajuste do valor do benefício.

Na verdade, os "novos" programas federais - "novos" por oposição àqueles no âmbito da LOAS - tiveram como ponto de partida a proposta de criação do programa de transferência de renda para famílias pobres com crianças na idade de escolaridade obrigatória, que fazia parte da plataforma de candidatura presidencial do Partido dos Trabalhadores (PT) às eleições de 1989. A proposta era especialmente atrativa por atenuar a insuficiência de renda presente para as famílias assistidas, melhorando de imediato seu nível de consumo privado e de bem-estar, ao mesmo tempo em que atacava as raízes da pobreza e da desigualdade ao incentivar a escolarização das crianças oriundas de famílias de baixa renda. Deste modo, o objetivo era também atuar sobre as causas estruturais da pobreza de forma a reduzi-la no futuro. Operacionalmente, a proposta tinha a vantagem de focalizar o benefício num subconjunto de famílias pobres, reduzindo significativamente a população beneficiária, ${ }^{4}$ o que amenizava os problemas de financiamento e de gestão do programa.

Com a derrota do PT nas eleições presidenciais, as iniciativas pioneiras de implementação efetiva de um programa deste tipo, que passou a ser conhecido como Bolsa Escola, se deram a nível local, mas em áreas onde a incidência de pobreza não atingia níveis críticos, a abrangência de serviços públicos básicos se situava bem acima da média nacional e as restrições financeiras do poder local eram menos graves. ${ }^{5}$ A forma criteriosa de implementação desses programas pioneiros e sua consequente boa aceitação nos meios especializados levaram a que o programa fosse visto como uma panacéia para o problema da pobreza, ignorando a enorme gama de diferenciações que assume o fenômeno da pobreza no Brasil. Assim, por volta de 1996/1997, quando ficou evidente que os efeitos redistributivos do plano de estabilização tinham se esgotado e as condições de emprego e renda se mostravam inquietantes (Rocha, 2001), houve um grande número de iniciativas municipais no sentido de criar as bases legais para a

(4) Para que se tenha uma ideia do impacto da utilização do critério de focalização baseado na presença de crianças de 7 a 14 anos na família: enquanto o número de famílias com renda familiar per capita inferior a $1 / 2$ salário mínimo era de 769 mil nas áreas metropolitanas em 1996, apenas cerca da metade, ou 382 mil famílias, tinha crianças nesta faixa etária (Rocha, 1999).

(5) O programa implementado no Município de Campinas em 1995 veio se articular a um conjunto de políticas municipais de assistência social às famílias mais pobres, beneficiando cerca de 2.500 famílias. Já no Distrito Federal, o programa foi concebido de forma a se constituir no próprio centro articulador da política voltada para o segmento mais pobre da população local. Implementado progressivamente nas cidades satélites, o programa atendia cerca de 25 mil famílias no início de 1999, mas não teve continuidade após o governo de Cristóvão Buarque. 
implementação de programas de renda mínima financiados com recursos locais. Parte destas iniciativas resultou de promessas feitas no âmbito da campanha eleitoral para as prefeituras em final de 1996. Na maioria dos casos, foram ignoradas as condições necessárias para a implementação bem-sucedida deste tipo de programa. Mesmo levando em conta apenas a restrição financeira, poucos municípios no país dispunham de recursos necessários para implementar o programa em escala compatível com o da incidência de pobreza local. ${ }^{7}$ Ademais, a maioria dos municípios optou por replicar o desenho do bem-sucedido programa do Distrito Federal, inclusive no que tange ao valor do benefício mensal a ser concedido, equivalente a um salário mínimo, o que, nos municípios mais pobres, era incompatível tanto com o nível de renda das famílias como com a capacidade financeira local (Lavinas; Rocha; Varsano, 1998).

Foi neste contexto de proliferação atabalhoada de iniciativas locais sem reais condições de operacionalização e de expectativa quanto à votação pela Câmara Federal do Projeto de Lei 2.561 que o governo federal fez aprovar um projeto de lei que previa o apoio financeiro aos governos municipais para a implementação de programas de garantia de renda mínima associados a ações socioeducativas (Lei 9.533 de 10 de dezembro de 1997). O governo cobriria 50\% dos gastos com as transferências, mas a iniciativa de implementação pertencia ao município. Os resultados foram pífios: poucos municípios se interessaram pela parceria e, quando acordos entre governo local e federal foram celebrados, houve múltiplos problemas operacionais, do cadastramento ao recebimento dos recursos federais e à logística de pagamento às famílias (Rocha; Garcia, 2001).

Dadas as evidências irrefutáveis do fracasso do modelo de parceria financeira entre governo federal e local, assim como da incapacidade técnica e gerencial da maioria dos municípios, principalmente dos mais pobres, para implementar um programa deste tipo, o governo federal relança, em 2001, o Bolsa Escola em novas bases, cobrindo $100 \%$ do valor dos benefícios, o que resolve a questão financeira. Permanecem como responsabilidade local as tarefas de cadastramento e seleção dos beneficiários, assim como a garantia de infraestrutura para o cumprimento da condicionalidade educacional. ${ }^{8}$

Apesar de o programa Bolsa Escola ter sido o mais importante, outros programas de transferência de renda foram criados pelo governo federal a partir de meados dos anos noventa, atendendo a objetivos específicos. Em 1996, o

(7) Apenas 40 dos quase 6.000 municípios brasileiros teriam condições de pagar meio salário-mínimo por família da clientela alvo do programa, comprometendo menos de $5 \%$ da sua receita corrente em 1996 (Lavinas; Rocha; Varsano, 1998).

(8) Era obrigatória a frequência à escola para as crianças de 7 a 14 anos das famílias beneficiárias, o que permaneceu como traço característico, embora na prática não relevante, dos programas do mesmo tipo que se seguiram. A respeito do impacto da condicionalidade educacional no Bolsa Escola, ver Schwartzman (2005). 
Programa de Erradicação do Trabalho Infantil (PETI) foi instituído para enfrentar questões graves de trabalho penoso de crianças. ${ }^{9}$ Em 2001, foi criado o Auxílio Gás de modo a compensar as famílias de baixa renda pela eliminação do subsídio embutido no preço ao consumidor do gás de cozinha. Também em 2001, o Bolsa Alimentação, sob a responsabilidade do Ministério da Saúde, tinha o foco complementar ao Bolsa Escola, atendendo a famílias pobres com crianças de zero a seis anos. ${ }^{10}$

A superposição, legítima ou ilegítima, de programas de transferência de renda no que concerne ao atendimento da população pobre tornou evidente a necessidade de coordenação e controle através da criação de um cadastro único. ${ }^{11}$ Criado em 2001, sua implementação foi muito lenta, de modo que ao final do período Cardoso, em 2002, os "novos" programas de transferência renda continuavam atrelados a organismos governamentais diversos, sem qualquer coordenação entre si.

Decisões tomadas no início do governo Lula modificaram de forma fundamental a política de transferência de renda dos "novos" programas. Por um lado, a clientela alvo se ampliou significativamente, já que se universalizou a elegibilidade ao benefício para todas as famílias de baixa renda. Assim, passaram a se qualificar para o recebimento de $\mathrm{R} \$ 50$ /mês do novo Cartão Alimentação todas as famílias com renda familiar per capita (RFPC) inferior a um quarto do salário mínimo. ${ }^{12}$ Em consequência, a população alvo dos novos programas de transferência de renda praticamente dobrou. ${ }^{13}$ Por outro lado, havia o objetivo explícito de unificação dos novos programas. Após um início confuso e semeado de contradições conceituais e operacionais, em outubro do mesmo ano o programa de transferência de renda foi relançado sob a denominação de Bolsa Família (BF), para o qual foram estabelecidas novas regras: houve elevação do teto de renda familiar per capita para fins de elegibilidade, que foi desatrelado do salário mínimo, assim como mudança na forma de estabelecimento do valor do benefício, que passou a ser variável - de $\mathrm{R} \$ 15$ a $\mathrm{R} \$ 95$, conforme a renda da família e a presença de crianças. ${ }^{14}$

(9) Inicialmente, tratava-se do trabalho infantil em carvoarias do MT, tendo se expandido para o combate do trabalho infantil na cultura canavieira e de sisal, em casas de farinha etc.

(10) O Auxílio Gás foi criado pela MP 18/2002; o Bolsa Alimentação pela MP 2206/2001 (MDS, 2004).

(11) O Cadastro Único foi criado em julho de 2001 e regulamentado em outubro do mesmo ano.

(12) O Cartão Alimentação era o componente de transferência de renda no âmbito do programa social mais amplo do governo Lula, denominado Fome Zero e criado em fevereiro de 2003.

(13) O governo estimava inicialmente a população alvo em 9,9 milhões de famílias.

(14) Esta mudança na forma de cálculo do benefício representou um aumento de cerca de $20 \%$ do seu valor médio. 
Tabela 1

Benefícios e dispêndio dos programas federais de transferência de renda - setembro 2004

\begin{tabular}{c|c|c}
\hline Programas & $\mathrm{N}^{\mathrm{o}}$ de Benefícios Pagos & Dispêndio (R\$ mil) \\
\hline Novos "Programas" & 10.295 .493 & 465.986 \\
\hline Bolsa Escola & 3.381 .486 & 78.778 \\
\hline Bolsa Família & 5.035 .660 & 346.687 \\
\hline Cartão Alimentação & 322.317 & 16.116 \\
\hline Bolsa Alimentação & 251.459 & 4.836 \\
\hline Auxílio Gás & 1.304 .571 & 19.569 \\
\hline Benefícios Assistenciais & 2.565 .857 & 674.733 \\
\hline LOAS & 1.983 .788 & 518.538 \\
\hline RMV e PMV & 582.069 & 156.194 \\
\hline Total Geral & 12.861 .350 & 1.140 .719 \\
\hline
\end{tabular}

Nota: Não foi possível obter a informação sobre o PETI.

Fonte: Registros administrativos do MDS.

No entanto, ao final de 2004, cerca de um ano após a criação do Bolsa Família como "guarda-chuva" dos "novos" programas de transferência de renda federais, a unificação estava longe de se realizar. O Bolsa Família tinha se expandido muito, atingindo, segundo o MDS, 5 milhões de famílias, seja por incorporação de beneficiários de programas preexistentes, seja pela inclusão de novas famílias. No entanto, o Bolsa Escola e o Auxílio Gás, que se superpunham de forma importante, eram os programas com clientelas ainda muito amplas, 1,3 milhão e 3,4 milhões, respectivamente. Do ponto de vista do dispêndio, os "novos" programas de transferência ainda representavam um dispêndio de cerca de $10 \%$ inferior ao da LOAS devido à enorme diferença nos valores dos benefícios. ${ }^{15}$ A Tabela 1 apresenta o número de benefícios e o dispêndio com o seu pagamento, segundo programas, em setembro de 2004, tendo por base os registros administrativos do governo federal. Essas informações compõem um quadro de referência da institucionalidade e cobertura desses programas quando a PNAD investigou, pela primeira vez, as características da clientela dos programas de transferência de renda através de um questionário suplementar com 16 quesitos.

O processo de unificação dos "novos" programas sob o BF continua desde então, tendo sido alcançada, no final de 2006, a meta de atendimento de 11 milhões de domicílios. No final de 2008, a clientela atendida permanecia neste mesmo nível, mas o dispêndio vem aumentando em função de ajustes dos parâmetros de renda e do valor dos benefícios, assim como da alteração do desenho do programa para incluir um benefício específico para os jovens de $16 \mathrm{e}$ 17 anos. Ainda assim, o dispêndio anual com o programa em 2008,

(15) O benefício da LOAS correspondia ao salário mínimo ( $\mathrm{R} \$ 260)$ e o do BF variava entre R\$15 e R\$ 95 
correspondendo a $\mathrm{R} \$ 10,6$ bilhões, tem uma participação marginal - 0,37\% - no PIB daquele ano.

\section{Evolução do programa Bolsa Família entre 2004 e 2006}

As PNADs de 2004 e de 2006 incluem ambas um questionário suplementar que investiga, para todas as famílias da amostra, o eventual recebimento de transferências de renda assistenciais. Enquanto no questionário de 2004 investigava-se especificamente tanto o BF como os demais programas que o precederam, como apresentado na Tabela 2, em 2006 apenas o BF e o PETI são listados entre os "novos" programas. Considerando especificamente a frequência de respostas positivas quanto a benefícios pagos pelo Bolsa Família, a PNAD revela que seu número quadruplica entre 2004 e 2006, passando de 2,0 milhões a cerca de 8,1 milhões, respectivamente. ${ }^{16}$

Na verdade, não se trata de uma expansão real da cobertura do BF, já que os dados da PNAD 2004 relativos ao programa estavam obviamente subestimados: como a implementação do BF era relativamente recente, uma parte significativa dos domicílios investigados acabou por declarar estar recebendo benefícios dos programas anteriores, quando, administrativamente, já estavam recebendo do BF. Por esta razão, não só o número de declarações relativas ao BF é menor na PNAD do que nos registros do MDS, como se verificou, em geral, um descasamento das informações oriundas das duas fontes (Tabela 2). No caso do BF, o número obtido da PNAD corresponde a cerca de $41 \%$ do número de benefícios com pagamento autorizado pelo MDS em setembro 2004. No entanto, o mais relevante é observar que o número total de benefícios pagos pelos novos programas é semelhante segundo as duas fontes, cerca de 11 milhões (Rocha, 2008a).

Tabela 2

Número de transferências recebidas e empenhadas

"Novos" Programas - 2004

\begin{tabular}{l|c|c}
\hline \multirow{2}{*}{ Programa } & \multicolumn{2}{|c}{ Número de Transferências (mil) } \\
\cline { 2 - 3 } & Recebidas (PNAD) & Empenhadas (MDS) \\
\hline Bolsa Família & 2.089 & 5.036 \\
\hline PETI & 367 & 929 \\
\hline Total Parcial & 2.456 & 5.965 \\
\hline Bolsa Escola & 3.803 & 3.381 \\
\hline Cartão Alimentação & 752 & 322 \\
\hline Auxílio Gás & 3.491 & 1.305 \\
\hline Bolsa Alimentação & 536 & 251 \\
\hline Total "Novos” Programas & 11.038 & 11.224 \\
\hline
\end{tabular}

Fonte: MDS e PNAD 2004.

(16) Evidências empíricas analisadas nesta seção encontram-se também em Rocha (2008b), que compara as características de operacionalização dos novos programas, e do Bolsa Família em particular, aos do programa preexistente de Benefícios de Prestação Continuada associado à Lei Orgânica de Assistência Social (LOAS). 
Com o objetivo de examinar a evolução da cobertura dos novos programas estritamente do ponto de vista do número de benefícios concedidos, apresenta-se a seguir a contraposição do número de benefícios conforme obtidos da PNAD e dos registros administrativos do MDS para o mês de setembro de 2006 (Tabela 3). Na PNAD, foram investigados, entre os novos programas, apenas o BF e o PETI, já que se consideravam os outros "novos" programas devidamente integrados e reconhecidos como sendo do $\mathrm{BF} .^{17}$

A cobertura de 11 milhões de domicílios pelo BF foi divulgada com grande ênfase pelo governo, já que significava que o programa atingia sua meta quanto ao tamanho da clientela atendida ao final de 2006. No entanto, na comparação entre os dados da PNAD e do MDS, chama a atenção a diferença de 2,7 milhões entre o número de benefícios pagos segundo cada uma das fontes, 8,1 milhões e 10,9 milhões, respectivamente.

O número normalmente divulgado pelo MDS refere-se às transferências sob o enfoque financeiro do regime de competência, ${ }^{18}$ o que explica parte da diferença. Assim, embora o pagamento estivesse disponível, apenas 9,4 milhões do total dos 10,9 milhões de domicílios beneficiários fizeram o saque efetivamente no mês de setembro, sendo, portanto, captados pela pergunta da PNAD ("Em setembro de 2006, algum morador deste domicílio recebeu dinheiro do programa social Bolsa Família?"). ${ }^{19}$ A diferença remanescente entre os números captados pela PNAD e os dados em regime de caixa do MDS é sensivelmente menor, mas ainda acima de um milhão de famílias. Como a PNAD é uma pesquisa amostral, ocorre alguma imprecisão na contagem, ${ }^{20}$ mas a diferença remanescente é muito elevada para ser imputada apenas a razões amostrais. Naturalmente, esta diferença tem necessariamente algum impacto sobre as análises realizadas com base na PNAD, como as que serão feitas a seguir.

(17) O PETI responde a uma lógica própria, continuando, ainda em 2006, como um programa de transferência de renda administrado em separado. As informações do MDS evidenciam de forma inequívoca a participação marginal dos demais programas no número de transferências realizadas naquele mês - 139 mil ou $1,2 \%$ do total

(18) Regime de competência refere-se às transferências que tiveram a despesa correspondente efetivamente liberada no mês de setembro, com o respectivo pagamento disponível para saque junto à Caixa Econômica nos cinco últimos dias de setembro e nos cinco primeiros dias de outubro. Após a data do depósito, as famílias beneficiárias têm o prazo de três meses para sacar o benefício.

(19) Meus agradecimentos a Sergio Monteiro, do Ministério de Desenvolvimento Social, que teve o trabalho de recompor as informações de pagamento efetivo (regime de caixa) para o mês de setembro de 2006.

(20) Há que considerar que a PNAD cobre necessariamente de forma deficiente grupos populacionais em localização temporária, tais como acampamentos dos sem-terra, e que os resultados da análise são tanto mais afetados quanto mais intensamente estes grupos forem focados pelo programa de transferência de renda. 
Tabela 3

Transferências recebidas e empenhadas

"Novos" Programas - 2006

\begin{tabular}{l|c|c}
\hline \multirow{2}{*}{ Programa } & \multicolumn{2}{c}{ Transferências (mil) } \\
\cline { 2 - 3 } & Recebidas (PNAD) & Empenhadas (MDS) \\
\hline Bolsa Família & 8.126 & 10.961 \\
\hline PETI & 267 & 682 \\
\hline Total Parcial & 8.393 & 11.643 \\
\hline Bolsa Escola & $\ldots$ & 24 \\
\hline Cartão Alimentação & $\ldots$ & 107 \\
\hline Auxílio Gás & $\ldots$ & 11.782 \\
\hline \multicolumn{1}{c}{ Total Geral } & 8.393 & \\
\hline
\end{tabular}

Nota: (...) indica programas que não foram objeto de investigação pela PNAD

Fonte: MDS e PNAD 2006.

Com base na PNAD e à guisa de conclusão sobre a evolução da cobertura dos "novos" programas, pode-se afirmar que não teria então ocorrido uma ampliação significativa da cobertura do BF ou dos "novos" programas em geral entre 2004 e 2006. No entanto, houve indubitavelmente grandes avanços em termos de racionalização do sistema de transferências. Enquanto em 2004 havia, segundo a PNAD, uma significativa superposição dos programas, ${ }^{21}$ já que 11 milhões de benefícios dos "novos" programas eram pagos a 8,056 milhões de domicílios, o que significava uma média de 1,4 benefício por domicílio (Rocha, 2008a), em 2006 esta superposição estava significativamente reduzida.

Tabela 4

Superposição do BF com Outros Programas de Transferência de Renda Brasil, Regiões Norte e Nordeste - 2006 (mil domicílios)

\begin{tabular}{l|r|r|r|r|r|r}
\hline \multirow{2}{*}{ Situações } & \multicolumn{2}{|c|}{ Brasil } & \multicolumn{2}{c|}{ Norte } & \multicolumn{2}{c}{ Nordeste } \\
\cline { 2 - 7 } & No. & $\%$ & No. & $\%$ & No. & $\%$ \\
\hline Só Bolsa Família & 7.415 & 91,3 & 650,7 & 88,7 & 3.958 & 91,7 \\
\hline Bolsa Família e PETI & 100 & 1,2 & 6,7 & 0,9 & 76 & 1,8 \\
\hline Bolsa Família e LOAS & 237 & 2,9 & 28,9 & 3,9 & 141 & 3,3 \\
\hline Bolsa Família e Outros & 341 & 4,2 & 41,8 & 5,7 & 131 & 3,0 \\
\hline Outras Combinações & 24 & 0,3 & 5,2 & 0,7 & 8 & 0,2 \\
\hline \multicolumn{1}{c|}{ Total } & 8.126 & 100 & 733 & 100 & 4.314 & 100 \\
\hline
\end{tabular}

Fonte: PNAD 2006 (Tabulações especiais).

(21) Parte das superposições verificadas em 2004 era legítima: quando, após o recebimento do primeiro benefício, a renda domiciliar per capita (RDPC) permanecia abaixo do limite de renda estabelecido como limite pelo programa, o domicílio se qualificava a receber uma segunda transferência (Rocha, 2008a). Após a unificação dos novos programas sob o Bolsa Família, esta mecânica explica superposições legítimas entre o BF e o PETI, assim como entre o BF e os benefícios da LOAS. 
Alguma superposição de benefícios do $\mathrm{BF}$ com o de outros programas subsistia em 2006, mas não chegava a 10\%, embora sua frequência variasse muito entre regiões (Tabela 4). Dos domicílios que declararam receber transferência do $\mathrm{BF}$, apenas $1,2 \%$ eram também beneficiários do PETI, que é um programa que responde a uma lógica diferente e que se mantinha, em 2006, fora da esfera do MDS. No Nordeste, onde as condições de pobreza e a importância relativa da agricultura de subsistência resultam em incidência mais elevada do trabalho infantil penoso, a superposição do BF e do PETI se apresentava mais relevante. Individualmente, é com os benefícios da LOAS que os do BF têm maior superposição, especialmente na Região Norte, onde esta superposição chega a 3,9\%. Trata-se de sistemas de transferência distintos, com critérios, parâmetros e cadastros diversos, que, no médio prazo, tenderão a ser unificados. ${ }^{22}$

Cabe destacar que a grande maioria dos beneficiários do BF, isto é, 91,3\%, recebem apenas esta transferência, o que representa uma mudança importante em relação ao que se observava a partir dos dados do suplemento da PNAD 2004, quando apenas cerca da metade dos beneficiários do $\mathrm{BF}$ recebia somente $\mathrm{o} \mathrm{BF}$ (Rocha, 2008a). Assim, no que concerne à evolução da cobertura, embora não tenha havido, stricto sensu, a expansão da clientela como propalado, ocorreu a essencial unificação dos diversos programas sob o Bolsa Família. Neste sentido, a utilização sistemática do Cadastro Único para seleção, controle e acompanhamento do programa se constitui no avanço mais importante, que se reflete nos resultados da focalização.

No que concerne aos aspectos ligados à focalização do BF, cabe lembrar que a análise se baseia nos 8,1 milhões de domicílios que declararam receber a transferência do BF em 2006. Por hipótese, os domicílios não declarantes, embora beneficiários, têm características semelhantes às daqueles que se declararam beneficiários na PNAD. Isto deve ser considerado também quando se trata das análises dos resultados das transferências imputadas sobre os indicadores de pobreza e desigualdade, objeto da seção 3.

Ao analisar a focalização do BF, é importante destacar que, apesar dos frequentes destaques jornalísticos a respeito de casos específicos de desvio na concessão do benefício, foi consensual, desde a divulgação dos dados da PNAD 2004, que a focalização dos novos programas nos mais pobres era relativamente boa (Rocha, 2006; Soares et al., 2006). Este resultado não deixa de ser surpreendente, dadas a rapidez de implantação, a cobertura nacional altamente capilarizada e a descentralização no processo de seleção de um contingente tão grande de beneficiários, especialmente frente à reconhecida tradição clientelista/paternalista brasileira, que se faz mais evidente no que concerne a aspectos vinculados à questão social.

(22) A respeito da necessidade de unificação dos programas assistenciais, ver Rocha (2008b) 
No entanto, mesmo no contexto geral de boa focalização dos benefícios do BF, a PNAD 2004 permitiu dimensionar um número relevante tanto de domicílios beneficiados que na data da pesquisa tinham renda superior ao limite estabelecido pelo programa assim como a situação oposta, isto é, de domicílios elegíveis, mas não beneficiários do $\mathrm{BF}$.

No primeiro caso, tomando por base o nível de renda mais elevado para fins de elegibilidade, situado em R $\$ 100$ em 2004, a PNAD permitiu captar que $33,8 \%$ dos que declararam receber a transferência do BF tinham RDPC superior a $\mathrm{R} \$ 130$, valor impossível de atingir apenas com a adição do valor do benefício do programa à renda familiar dentro dos limites previstos (Rocha, 2008a). Assim, como o valor do beneficio mínimo era de $\mathrm{R} \$ 15$ para famílias com renda entre $\mathrm{R} \$ 50$ e $\mathrm{R} \$ 100$ e apenas uma criança, enquanto o máximo era de $\mathrm{R} \$ 95$ para famílias com RDPC igual ou inferior a $\mathrm{R} \$ 50$ e três crianças ou mais, a RDPC após o recebimento do beneficio não podia ser, a rigor, superior a $\mathrm{R} \$ 111,2 \mathrm{em}$ 2004. O limite de renda estabelecido em $\mathrm{R} \$ 130$ para fins de análise contém, portanto, uma folga para algum aumento de renda pelas famílias participantes do programa. Na verdade, é bem sabido que uma das características da pobreza é a oscilação do nível de renda ao longo do tempo. Neste sentido, é aceitável a variação da renda das famílias beneficiárias em torno do limite estabelecido pelo programa, já que a PNAD não capta a renda permanente, mas a renda percebida no mês de referência específico.

Uma vez disponíveis as informações do suplemento da PNAD 2006, examinou-se a evolução da focalização tendo como referência a PNAD 2004, utilizando os mesmos cortes de RDPC após o recebimento dos benefícios. Há que se levar em conta, no entanto, que em 2006 tinha havido aumento dos limites de RDPC, para que as famílias se qualificassem para o programa, de $R \$ 50$ para $R \$$ 60 e de $R \$ 100$ para $R \$ 120$, o que altera a característica do corte arbitrário da renda estabelecido em $\mathrm{R} \$ 130$ para fins de análise. No que concerne ao valor dos benefícios, apesar de ter havido inflação da ordem de $8 \%$ no período, ${ }^{23}$ os valores dos benefícios não sofreram modificação antes de 2007.

A comparação entre 2004 e 2006 mostra que, como era de se esperar, aumentou a participação no conjunto total de beneficiários dos domicílios com RDPC superior a $\mathrm{R} \$ 130$, que atingem, neste último ano, quase a metade da clientela atendida pelo BF (Tabela 5). Este resultado se deve a diversos fatores. Por um lado, reflete a inflação do período, além do aumento generalizado da renda real entre 2004 e 2006, que, reconhecidamente, beneficiou de forma mais acentuada a população na base da distribuição de rendimentos. Por outro lado, reflete a manutenção do corte de $\mathrm{R} \$ 130$ frente ao aumento do limite de renda para

(23) Variação de setembro 2004 a setembro de 2006 (INPC/IBGE). 
fins de elegibilidade de $\mathrm{R} \$ 100$ para $\mathrm{R} \$ 120 \mathrm{em}$ meados de 2006. Em contrapartida, reduziu-se a participação dos domicílios com renda inferior a $\mathrm{R} \$ 100$, em especial na faixa entre $\mathrm{R} \$ 50$ e $\mathrm{R} \$ 100$ (de $34 \%$ para $24 \%$ ). Estes resultados não são em si desfavoráveis, devendo ser analisados em conjunção com a evolução da mudança da cobertura dos domicílios elegíveis "a descoberto" situados na base da distribuição. Na verdade, na análise dos dados de 2004, havia chamado a atenção o contingente de quase 2,4 milhões de domicílios com RDPC acima de R $\$ 130$ em contraponto ao fato de que havia ainda cerca de 2 milhões que se situavam na faixa abaixo de $\mathrm{R} \$ 50$ sem receber a transferência de renda do $\mathrm{BF}$.

Tabela 5

Domicílios beneficiários por faixa de Renda Domiciliar per Capita (RDPC)

Brasil, 2004 e 2006

\begin{tabular}{|c|c|c|c|c|c|c|}
\hline \multirow{3}{*}{ RDPC } & \multicolumn{6}{|c|}{ Brasil } \\
\hline & \multicolumn{2}{|c|}{2004} & \multicolumn{2}{|c|}{2006} & \multirow{2}{*}{$\Delta$} & \multirow{2}{*}{$\Delta \%$} \\
\hline & $\mathrm{N}^{\mathrm{o}}$. (mil) & Part. (\%) & $\mathrm{N}^{\circ}$. (mil) & Part. (\%) & & \\
\hline 0 a 50 & 1.367 & 17,2 & 1.012 & 12,6 & -355 & $-26,0$ \\
\hline Mais de 50 a 100 & 2.698 & 34,0 & 1.958 & 24,4 & -740 & $-27,4$ \\
\hline Mais de 100 a 130 & 1.191 & 15,0 & 1.210 & 15,1 & 19 & 1,6 \\
\hline Mais de 130 & 2.677 & 33,7 & 3.857 & 48,0 & 1.179 & 44,0 \\
\hline Total & 7.934 & 100 & 8.037 & 100 & 103 & 1,3 \\
\hline
\end{tabular}

Nota: Exclusive domicílios com informação de RDPC missing. Em 2004 inclui todos os domicílios que recebem benefícios dos "novos" programas. Em 2006 refere-se aos domicílios que declararam receber o $\mathrm{BF}$.

Fonte: PNAD 2004 e 2006 (Tabulações especiais).

Tabela 6

Evolução do número de domicílios elegíveis não beneficiários do Bolsa Família Brasil, 2004 e 2006

\begin{tabular}{|c|c|c|c|c|c|c|c|c|c|}
\hline \multirow{3}{*}{ Situações } & \multicolumn{9}{|c|}{ Domicílios (mil) } \\
\hline & \multicolumn{3}{|c|}{ Até R\$ 50/60* } & \multicolumn{3}{|c|}{$\begin{array}{c}\text { Mais de } \mathrm{R} \$ 50 / 60 \\
\text { a } \mathrm{R} \$ 100 / 120^{* *}\end{array}$} & \multicolumn{3}{|c|}{ Total } \\
\hline & 2004 & 2006 & $\Delta \%$ & 2004 & 2006 & $\Delta \%$ & 2004 & 2006 & $\Delta \%$ \\
\hline $\begin{array}{l}\text { Não recebe nenhum } \\
\text { benefício }\end{array}$ & 1.779 & 934 & $-47,5$ & 2.738 & 2.154 & $-21,3$ & 4.517 & 3.088 & $-31,6$ \\
\hline Recebe só LOAS/BPC & 7 & 5 & $-23,3$ & 50 & 50 & $-0,2$ & 57 & 55 & $-3,0$ \\
\hline Recebe só PETI & - & 12 & - & - & 35 & - & - & - & - \\
\hline Outros $* * *$ & 139 & 48 & $-65,1$ & 246 & 133 & $-46,0$ & 385 & 181 & $-52,9$ \\
\hline Total & 1.925 & 1.000 & $-48,1$ & 3.034 & 2.371 & $-21,8$ & 4.959 & 3.371 & $-32,0$ \\
\hline \multicolumn{10}{|c|}{ 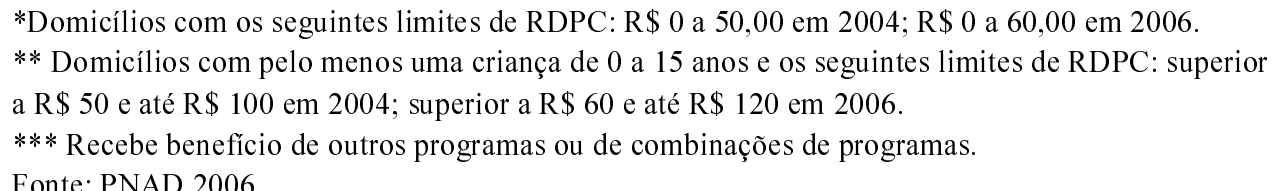 } \\
\hline
\end{tabular}


Uma vez disponíveis os dados do Suplemento de 2006, examinou-se então o segundo aspecto relevante do ponto de vista da focalização: a cobertura dos domicílios que, embora elegíveis, não recebiam o BF. Os dados da Tabela 6 mostram que houve um declínio significativo do número deles em relação a 2004 - menos 32\%. Ainda assim, 3,4 milhões domicílios elegíveis não recebiam o $\mathrm{BF}$ em 2006, sendo que um milhão destes se situava na faixa de renda mais baixa, isto é, com RDPC abaixo de $\mathrm{R} \$ 60$ per capita. Cabe destacar que a queda do número de elegíveis não beneficiários se deu de forma mais acentuada na faixa de renda mais baixa, o que se explica não só por eventuais melhorias de focalização do programa, mas por aumentos da renda que ocorreram independentemente do BF. De qualquer maneira, é um fato a celebrar a redução - absoluta e relativa - da clientela desassistida pelo BF entre os mais pobres no período de 2004 a 2006.

As evidências apresentadas nesta seção sobre a evolução do número de domicílios atendidos, em conjunto com aquelas sobre a focalização do BF, levam a algumas conclusões.

Primeiro, é possível afirmar que a redução do número de domicílios elegíveis, mas não beneficiários do BF, em pouco mais de 2 milhões de domicílios entre 2004 e 2006 não se deveu preponderantemente à expansão do programa, que incorporou pouco mais de 337 mil domicílios, ${ }^{24}$ mas principalmente ao aumento generalizado da renda na base da distribuição. Segundo, que, se não houve expansão relevante, foi de importância crucial o processo de unificação dos "novos" programas sob o BF, eliminando a superposição desordenada de benefícios que prevalecia anteriormente. Terceiro, a redução do número de domicílios elegíveis não beneficiários não pode ser associada a uma melhoria na focalização, já que houve uma expansão da ordem de 1,4 milhão do número de domicílios beneficiários com RDPC superior a $\mathrm{R} \$ 130$, enquanto se reduzia em 730 mil o número absoluto dos domicílios com rendimento nas duas faixas de RDPC abaixo de R $\$ 100$. O aumento dos domicílios atendidos com renda superior a $\mathrm{R} \$ 130$ corresponde, portanto, a mais de três vezes e meia os 337 mil domicílios incorporados ao programa entre 2004 e 2006. Quarto, a melhoria da renda que ocorreu no período contribuiu para melhorar os índices de cobertura do programa, principalmente nas faixas de renda mais baixa, mas ainda subsiste o desafio de atender a cerca de um milhão de domicílios elegíveis, mas ainda não beneficiários do programa, que declararam RDPC abaixo de R \$ 60/mês em setembro de 2006.

(24) No período em questão, o MDS realizou inclusão e exclusão de domić́lios por meio de um processo contínuo de seleção e recadastramento, que ocorreu paralelamente à unificação dos novos programas sob o BF. Deste modo, o aumento da cobertura em 337 mil domicílios corresponde ao aumento líquido do número de domicílios atendidos entre 2004 e 2006. 


\section{Impactos do Bolsa Família sobre a pobreza - potencialidades e limites}

É irrefutável que a pobreza e a desigualdade vêm diminuindo no Brasil de forma sustentada desde 2004 - o que as informações da PNAD 2007 vêm confirmar $^{25}$ - e que as transferências de renda assistenciais, em geral, e o BF, em particular, têm contribuído para esta evolução favorável. No entanto, na medida em que o BF expande a sua cobertura e que o número de domicílios elegíveis a descoberto diminui, reduz-se concomitantemente o potencial do programa de, mantendo as regras em vigor em 2006, levar a reduções adicionais da pobreza e da desigualdade.

O objetivo desta seção é ilustrar alguns aspectos relativos a possíveis impactos do programa, utilizando imputações simuladas de benefícios do BF. Os impactos sobre pobreza medidos nesta seção referem-se à subpopulação pobre delimitada a partir de linhas de pobreza baseadas nos valores mínimos do consumo observado entre populações de baixa renda e diferenciadas de modo a levar em conta a diversidade de estruturas de consumo e de preços ao consumidor entre regiões e áreas de residência do país (ver os valores das linhas de pobreza relativas a setembro de 2006 no Anexo 1). Para fins de análise de impacto do programa, foram utilizadas 24 linhas de pobreza diferenciadas, enquanto o BF e outros programas de transferência usam - aliás, como é adequado para a operacionalização -, parâmetros de renda idênticos para a seleção de beneficiários, qualquer que seja o seu local de residência.

Como visto na seção 2, em setembro de 2006 havia no país cerca de 3,4 milhões de domicílios que atendiam às condições do programa quanto à RDPC e à presença de crianças, mas que não recebiam o BF. A Simulação A consiste em verificar o efeito da imputação dos valores cabíveis - isto é, segundo as regras do BF em vigor em setembro de 2006 - a cada um desses domicílios sobre os indicadores habituais de pobreza (Foster; Greer; Thorbecke, 1984). Dadas as características conceituais dos indicadores considerados - número de pobres, intensidade da pobreza e desigualdade entre os pobres - esses efeitos são, naturalmente, tanto menores quanto mais restrita for a população que permanece indevidamente a descoberto, assim como quanto mais elevada e bem distribuída for a sua renda. A respeito dos resultados por região e por estrato, apresentados na Tabela 7, cabem algumas observações básicas.

(25) Segundo a PNAD, o coeficiente de Gini relativo à Renda Domiciliar caiu de 0,535 em 2004 para 0,521 em 2007 (domicílios particulares permanentes com rendimento). Também a proporção de pobres no Brasil vem caindo de forma sustentada desde o pico de $35,6 \%$ atingido em 2003 , situando-se em $25,1 \%$ em setembro de 2007 (Rocha, 2008a). 
Tabela 7

Efeito potencial de redução dos indicadores de pobreza como resultado da imputação de transferências do BF aos domicílios elegíveis não beneficiários, na data de referência Brasil, Regiões e Estratos de Residência

\begin{tabular}{|c|c|c|c|c|c|c|c|c|c|c|c|c|}
\hline \multirow{2}{*}{ Ano e Área } & \multicolumn{3}{|c|}{$\mathrm{N}^{\mathrm{o}}$ de Pobres } & \multicolumn{3}{|c|}{ Proporção de Pobres } & \multicolumn{3}{|c|}{ Razão do Hiato } & \multicolumn{3}{|c|}{ Hiato Quadrático } \\
\hline & Original & Simulado & Diferença & Original & Simulado & $\Delta \%$ & Original & Simulado & $\Delta \%$ & Original & Simulado & $\Delta \%$ \\
\hline \multicolumn{13}{|l|}{2006} \\
\hline Norte & 4.012 .650 & 3.876 .769 & 135.881 & 0,2697 & 0,2606 & $-3,39$ & 0,3597 & 0,3300 & $-8,25$ & 0,0510 & 0,0414 & $-18,80$ \\
\hline Nordeste & 20.202 .521 & 20.071 .745 & 130.776 & 0,3972 & 0,3946 & $-0,65$ & 0,4156 & 0,3902 & $-6,10$ & 0,0938 & 0,0826 & $-11,98$ \\
\hline Sudeste & 16.291 .658 & 16.256 .053 & 35.605 & 0,2120 & 0,2115 & $-0,22$ & 0,3742 & 0,3580 & $-4,33$ & 0,0436 & 0,0392 & $-10,19$ \\
\hline Sul & 2.788 .407 & 2.661 .416 & 126.991 & 0,1034 & 0,0987 & $-4,55$ & 0,3470 & 0,3200 & $-7,78$ & 0,0200 & 0,0158 & $-20,75$ \\
\hline Centro-Oeste & 3.636 .774 & 3.611 .075 & 25.699 & 0,2778 & 0,2758 & $-0,71$ & 0,3673 & 0,3496 & $-4,82$ & 0,0550 & 0,0482 & $-12,27$ \\
\hline Rural & 7.814 .950 & 7.467 .795 & 347.155 & 0,2708 & 0,2588 & $-4,44$ & 0,4135 & 0,3793 & $-8,28$ & 0,0641 & 0,0524 & $-18,35$ \\
\hline Urbano & 22.023 .641 & 21.915 .844 & 107.797 & 0,2253 & 0,2242 & $-0,49$ & 0,3719 & 0,3480 & $-6,44$ & 0,0457 & 0,0396 & $-13,43$ \\
\hline Metropolitano & 17.093 .419 & 17.093 .419 & 0 & 0,3051 & 0,3051 & 0,00 & 0,3989 & 0,3854 & $-3,37$ & 0,0683 & 0,0626 & $-8,28$ \\
\hline Brasil & 46.932 .010 & 46.477.058 & 454.952 & 0,2569 & 0,2544 & $-0,97$ & 0,3886 & 0,3668 & $-5,63$ & 0,0555 & 0,0486 & $-12,38$ \\
\hline \multicolumn{13}{|l|}{2004} \\
\hline Brasil & 57.424.596 & 56.929 .320 & 495.276 & 0,3242 & 0,3214 & $-0,86$ & 0,4119 & 0,3833 & $-6,94$ & 0,0764 & 0,0653 & $-14,49$ \\
\hline
\end{tabular}

Fonte: PNAD 2004 e PNAD 2006 (Tabulações especiais). 
A cobertura total dos 3,4 milhões domicílios elegíveis não beneficiários afeta muito pouco o número de pobres no Brasil, menos $1 \%$ ou 454 mil indivíduos pobres a menos. Isto se deve, em parte, ao fato de que, qualquer que seja a situação de renda e composição dos domicílios elegíveis ainda não cobertos, a imputação do benefício do BF só é passível de tirá-los da pobreza nas áreas rurais e nas áreas urbanas da Região Sul. Nas demais áreas urbanas e metropolitanas de todas as regiões, as regras do BF em conjunção com os valores das linhas de pobreza não permitem que, após receber o benefício, a renda domiciliar per capita passe a ser superior ao valor da linha de pobreza. ${ }^{26} \mathrm{O}$ impacto mais acentuado da imputação do benefício aos elegíveis não beneficiários se dá no Norte rural - de 663 mil para 527 mil pobres $(-20,5 \%)$ - em parte devido ao valor da linha de pobreza mais baixa. Na Região Nordeste o número absoluto de pobres se reduz quase com a mesma intensidade que no Norte - 131 mil e 136 mil indivíduos pobres a menos, respectivamente -, mas a queda relativa é de apenas $0,65 \%$ do total de pobres na região antes da imputação. É provável que a cobertura do programa no Norte rural apresente dificuldades devido à ocupação de baixa densidade numa área de grande extensão territorial.

A redução do hiato de renda mede a melhoria da renda daqueles que permanecem pobres depois da imputação, portanto não leva em conta a melhoria da renda dos que deixaram de ser pobres. O efeito é bem mais acentuado $(-5,6 \%)$ do que o que se verificou sobre o indicador de proporção $(-0,97 \%)$, mas, como é de se esperar, está longe de reduzir significativamente o hiato, apesar de o valor imputado aos domicílios elegíveis - R \$ 171,4 milhões - corresponder a cerca de $29 \%$ do valor efetivamente transferido pelo BF em setembro de $2006 .^{27}$

Já o hiato quadrático mostra um declínio ainda mais acentuado (-12,38\%), pois, além de incorporar as reduções da proporção e do hiato de renda, é afetado

(26) Examinemos alguns exemplos do mecanismo de impacto do benefício do BF sobre o número de pobres numa determinada área. Entre as áreas não rurais, apenas na área urbana da Região Sul o valor da linha de pobreza é baixo o suficiente - R\$ 119,14/pessoa/mês em setembro de 2006 - para que o BF tenha algum impacto sobre o número de pobres. Assim, com o limite de renda de R\$120 em vigor desde 2006, todos os domicílios pobres com crianças na área urbana da Região Sul se qualificam para receber o benefício. Neste caso, qualquer benefício, mesmo o mais baixo de R\$ 15 para famílias com uma criança na faixa etária até 15 anos, permite que os domicílios ao nível de renda próximo do limite de R\$120 ultrapassem a linha de pobreza. Já para as demais áreas urbanas e metropolitanas, o recebimento do benefício do BF não permite em nenhuma hipótese que seja ultrapassada a linha de pobreza. Vejamos o caso de Minas Gerais e Espírito Santo, onde a linha de pobreza para as áreas urbanas é de R\$131,65, a segunda mais baixa do país. Se o domicilio tiver a RDPC mais alta possível para ser atendido pelo programa ( $\mathrm{R} \$ 120,00)$ e for formado por um adulto e três crianças, de modo a receber o benefício máximo para esta faixa de renda ( $3 \times \mathrm{R} \$ 15=\mathrm{R} \$ 45)$, o benefício elevaria a RDPC para $\mathrm{R} \$ 131,25$, portanto ainda bem abaixo da linha de pobreza da região. No caso de domicilio com a mesma composição na faixa de renda abaixo de $\mathrm{R} \$ 60$, o resultado final seria ainda mais adverso (RDPC de R\$ 60 antes da imputação do benefício e $\mathrm{R} \$ 83,7$ depois).

(27) Segundo informações do MDS, o valor transferido efetivamente em setembro de 2006 (regime de caixa) foi de $\mathrm{R} \$ 587,5$ milhões. 
pela queda da desigualdade entre os pobres: a imputação do benefício do BF a um número relativamente elevado de domicílios muito pobres, isto é, com RDPC abaixo de $\mathrm{R} \$ 100$, ao mesmo tempo em que as linhas de pobreza chegam ao nível de $\mathrm{R} \$ 266,15$ na região metropolitana de São Paulo, contribui para que a imputação reduza fortemente a desigualdade de renda entre os pobres. Este é o indicador preferencial para examinar mudanças da pobreza quando medida do ponto de vista da renda, mas, por ser de mais difícil entendimento, é geralmente relegado em prol do número e da proporção de pobres.

Finalmente, cabe observar que, em comparação com o mesmo tipo de simulação realizada em 2004, os indicadores de pobreza melhoraram muito, mas os impactos potenciais das imputações são semelhantes devido ao fato que o BF não avançou prioritariamente entre os mais pobres, como desejável, permanecendo ainda um contingente importante de elegíveis não beneficiários (cf. Tabelas 3 e 4).

A Simulação B refere-se ao impacto sobre os indicadores de pobreza da introdução de um novo benefício aos jovens de 16 e 17 anos, criado em início de 2008 e incorporado ao BF a partir de março do mesmo ano. Trata-se do benefício de $\mathrm{R} \$ 30$ concedido aos domicílios que, atendendo aos critérios de renda do BF, tivessem a presença de jovens de 16 e 17 anos frequentando a escola. A concessão do benefício, limitado a dois jovens por domicílio, além de aumentar o dispêndio do programa, reforçando seus impactos sobre pobreza e desigualdade, tem a função de dar um incentivo à continuidade do processo de escolarização na faixa etária onde o problema de abandono da escola é mais crítico. ${ }^{28}$

Cabe lembrar que o novo benefício altera o desenho do programa, já que cria um benefício de valor diferenciado, no caso de valor mais alto, para uma clientela anteriormente não diretamente assistida. Neste sentido, esta mudança introduzida no BF é conceitualmente diversa do ajuste dos parâmetros de renda em 2006 ou da atualização dos valores dos benefícios realizados em 2007 de forma a recompor o poder de compra da transferência frente à inflação. Apesar da alteração de desenho, o MDS optou por manter a mãe como recipiente do valor da transferência, ao invés de adotar a alternativa de pagar o novo benefício diretamente aos jovens. Embora a alternativa permitisse, sem dúvida, personalizar o incentivo escolar de forma mais direta, implicaria em complicações de ordem logística, com impactos adversos também sobre o custo de operação do programa.

A Simulação B, realizada utilizando as informações da PNAD de 2006, refere-se ao período em que o benefício aos jovens ainda não existia. $\mathrm{Na}$ Simulação B, o novo benefício é atribuído apenas aos domicílios que declararam já receber o BF e que tinham jovens de 16 e 17 anos. Optou-se por não levar em conta a situação do jovem quanto à frequência à escola, de modo a simular o efeito

(28) Sobre o abandono progressivo da escola a partir dos 12 anos e o baixo nível de escolaridade dos jovens brasileiros, ver Rocha (2007). 
potencial mais amplo do novo benefício, assumindo que, em função da mudança do programa, muitos jovens voltariam à escola.

Tabela 8

Simulações de impacto da imputação do benefício aos jovens de 16 e 17 anos

Brasil, 2006

\begin{tabular}{c|c|c|c|c}
\hline Cenários* & $\begin{array}{c}\text { Número } \\
\text { de Pobres }\end{array}$ & $\begin{array}{c}\text { Proporção } \\
\text { de Pobres }\end{array}$ & Hiato de Renda & Hiato Quadrático \\
\hline Original & 46.932 .010 & 0,25693 & 0,38865 & 0,05553 \\
\hline Simulação A & 46.477 .058 & 0,25444 & 0,36677 & 0,04865 \\
\hline Diferença & -454.952 & $-0,97$ & $-5,63$ & $-12,38$ \\
\hline$\Delta \%$ & & & & \\
\hline & & 0,25609 & 0,38510 & 0,05450 \\
\hline Simulação B & 46.777 .330 & $-0,33$ & $-0,91$ & $-1,84$ \\
\hline Diferença & -154.680 & & & \\
\hline$\Delta \%$ & & &
\end{tabular}

* Diferença e Variação entre cada simulação e a situação original.

Fonte: PNAD 2006 (Tabulações especiais).

A imputação do benefício aos jovens na Simulação B permite uma redução de 154 mil pobres, cerca de $33 \%$ da redução obtida com a Simulação A, que imputou o benefício básico aos elegíveis não beneficiários (Tabela 8). Ao aumentar o valor global do benefício recebido para aqueles domicílios que já recebem o BF, parcela significativa dos que têm RDPC superior a $R \$ 130,00$ (48\%), é possível que um número relativamente importante deles ultrapasse a linha de pobreza. No entanto, os efeitos do benefício adicional aos jovens são fracos sobre o hiato de renda $(-0,91 \%)$, até porque o declínio do número de pobres tem algum impacto adverso sobre o hiato. Já a redução do hiato quadrático é naturalmente baixa $(-1,84 \%)$ porque o benefício adicional aos jovens, ao replicar a atual distribuição BF, não alcança preponderantemente os mais pobres entre os pobres, tendo, portanto, um efeito muito atenuado sobre a desigualdade de renda entre eles. Fica claro, portanto, que mais importante do que ampliar o valor para a clientela atendida é garantir a cobertura dos elegíveis não beneficiários, dando prioridade àqueles com RDPC mais baixa.

A comparação dos resultados das simulações A e B sobre os indicadores de pobreza mostra, de forma inequívoca, que atender aos domicílios elegíveis não beneficiários é a opção mais adequada se o objetivo for o de reduzir pobreza, qualquer que seja o indicador de pobreza utilizado.

No entanto, é certamente fundamental verificar qual são as diferenças entre as duas simulações em termos de custo/benefício, considerando como custo o dispêndio total realizado e como benefício as reduções obtidas nos indicadores de pobreza. A Tabela 9 mostra que, em termos de redução do número de pobres, o 
custo unitário da Simulação A é muito mais adverso do que o da Simulação B. Como se viu, isto é compreensível, já que o pequeno valor unitário do BF não permite praticamente reduzir o número de pobres nas áreas urbanas $\mathrm{e}$ metropolitanas, além do fato de que o pagamento do benefício aos domicílios na base da distribuição também é incapaz de tirá-los da pobreza.

Tabela 9

Custo simulado da redução do número de pobres

( $\mathrm{R} \$$ por indivíduo pobre a menos)

\begin{tabular}{l|c|c|c}
\hline Simulações & $\begin{array}{c}\text { Custo Total } \\
\text { (R\$ mil) }\end{array}$ & $\begin{array}{c}\text { Redução do número } \\
\text { de Pobres }\end{array}$ & Custo Unitário (R\$) \\
\hline Simulação A & 171.359 & 454.952 & 376,65 \\
\hline Simulação B & 30.706 & 154.680 & 198,51 \\
\hline
\end{tabular}

Fonte: PNAD 2006 (Tabulações especiais).

Os indicadores de razão do hiato e de hiato quadrático revelam um quadro bem diferente (Tabela 10). A Simulação A aparece como mais a vantajosa quanto ao custo para reduzir os indicadores, embora os diferenciais entre as duas simulações se estreitem muito em relação ao verificado quanto à redução do número de pobres. Como o custo total associado à Simulação A é alto, pode-se argumentar a seu favor que fazer chegar o programa aos elegíveis na base da distribuição de rendimentos pode não ser fácil e imediato, o que necessariamente dilui no tempo o impacto em termos de dispêndio total, que se mostrou 5,5 vezes mais elevado do que o da Simulação B. Já o benefício aos jovens da Simulação B tem impacto imediato. O MDS previa para março de 2008, primeiro mês de concessão do novo benefício, um dispêndio adicional de $\mathrm{R} \$ 34,7$ milhões.

É importante salientar que as mudanças na forma de operar o BF, apresentadas nas simulações $\mathrm{A}$ e $\mathrm{B}$, não são alternativas. A criação do benefício aos jovens gera o direito a ele também para os domicílios elegíveis não beneficiários. Neste caso, impactos e custos são maiores, pois implicam adicionar aos resultados da Simulação A os custos e benefícios de atender também os jovens dos domicílios elegíveis e não beneficiários com a nova transferência.

Tabela 10

Custo simulado da redução dos indicadores de hiato da renda

\begin{tabular}{|c|c|c|c|c|c|}
\hline \multirow[b]{2}{*}{ Simulações } & \multirow[b]{2}{*}{$\begin{array}{l}\text { Custo Total } \\
\text { (R\$ mil) }\end{array}$} & \multicolumn{2}{|c|}{ Hiato de Renda } & \multicolumn{2}{|c|}{ Hiato Quadrático } \\
\hline & & $\begin{array}{c}\text { Redução } \\
\text { total } \\
(\%)\end{array}$ & $\begin{array}{l}\text { Custo por ponto } \\
\text { percentual } \\
\text { reduzido } \\
\text { (R\$ mil) }\end{array}$ & $\begin{array}{c}\text { Redução } \\
\text { total } \\
(\%)\end{array}$ & $\begin{array}{l}\text { Custo por ponto } \\
\text { percentual } \\
\text { reduzido } \\
\text { (R\$ mil) }\end{array}$ \\
\hline Simulação A & 171.359 & 5,63 & 30.448 & 12,38 & 13.839 \\
\hline Simulação B & 30.706 & 0,91 & 33.682 & 1,84 & 16.699 \\
\hline
\end{tabular}

Fonte: PNAD 2006 (Tabulações especiais). 
Foi feita então uma nova simulação - a Simulação C -, com o objetivo de mostrar os impactos da concessão tanto do benefício básico como do benefício aos jovens para os domicílios elegíveis e não beneficiários em setembro de 2006 . No Anexo 2, apresentam-se as tabelas comparativas dos resultados das três simulações. Naturalmente, na Simulação C acentuam-se os impactos sobre os indicadores em comparação à Simulação A. Observa-se também que o custo unitário de reduzir o número de pobres é menor do que na Simulação A - afinal, estamos dando um incremento de renda aos domicílios que já recebem o benefício básico. Mas, do ponto de vista dos indicadores de hiato, o benefício adicional aos jovens permanece menos eficiente para reduzir a pobreza do que garantir a cobertura básica de todos os domicílios elegíveis.

\section{Considerações finais}

Em função das suas características de desenho e de operação, o programa Bolsa Família vem sendo acompanhado com atenção por todos os que se interessam em buscar soluções para os problemas de desigualdade e pobreza, seja no país, seja no exterior. No entanto, uma boa parte da avaliação positiva do programa advém de traços específicos que ele incorpora, tornando-o adequado às condições de vida e características do desenvolvimento socioeconômico brasileiro.

Um traço básico do desenho do BF é o fato de ele partir do pressuposto de que a transferência de renda é um mecanismo legítimo de política social no Brasil. Isto porque o país já alcançou um nível de renda per capita tal que torna a desigualdade o fator explicativo básico da persistência da pobreza. Neste sentido, pequenas transferências bem focalizadas têm forte impacto sobre a desigualdade de renda, apesar de representarem um dispêndio baixo em relação ao PIB do país, sendo, portanto, facilmente pagáveis. Implementar um programa assistencial de transferência de renda implica também reconhecer que, numa economia urbana e monetizada, dispor de renda monetária é condição de cidadania e que cabe ao beneficiário da transferência de cunho assistencial decidir quanto ao uso do benefício. Pobreza no Brasil não é mais, felizmente, uma questão de sobrevivência física, que se encontra restrita a bolsões espacialmente bem delimitados.

Outro traço característico de desenho do BF, frequentemente destacado pelos analistas acadêmicos, são as chamadas "condicionalidades" do programa em termos de frequência à escola e cuidados com a saúde. Trata-se de um traço essencial do programa do ponto de vista conceitual e estratégico, pois permitiria que o BF não somente aliviasse a pobreza presente, mas operasse no sentido de romper o círculo vicioso da pobreza mais adiante. No caso brasileiro, o atendimento dessas condicionalidades não representou uma demanda adicional desafiadora sobre as áreas de saúde e educação. Por exemplo, no início desta 
década, 96,5\% das crianças entre 7 e 14 anos já frequentavam a escola e a cobertura vacinal já era reconhecidamente excelente. Isto significa que já se havia avançado bastante na provisão de serviços sociais, mas que a elevação da renda dos mais pobres via inserção adequada no mercado de trabalho esbarrava em obstáculos ligados à modernidade e dualidade da economia brasileira que não vinham sendo resolvidos. Então, no caso brasileiro, aumentar a renda dos pobres via transferência assistencial era o caminho mais óbvio e direto de melhorar sua condição de vida.

A boa avaliação que tem tido o programa também resulta de algumas de suas características de operacionalização. Primeiro, cabe destacar a continuidade dos "novos" programas que, a partir da sua implantação inicial em nível local, em meados da década de noventa, foram crescendo e sendo ajustados paulatinamente às necessidades e dificuldades encontradas. A colaboração entre governo federal e municipal permanece, mas os mecanismos de controle e avaliação estão sendo permanentemente reforçados. O uso do cartão magnético para saque do valor transferido diretamente no terminal bancário, que só foi possível em função da capilaridade e modernidade do sistema bancário brasileiro, tornou automático e impessoal o pagamento do benefício, portanto menos vulnerável ao seu uso político.

Finalmente, as características de operacionalização se vinculam estreitamente às questões de cobertura e focalização que foram tratadas especificamente neste texto. A escala atingida pelo programa, 11 milhões de benefícios pagos mensalmente segundo o MDS, dos quais pouco mais de 8 milhões foram captados pela PNAD em setembro de 2006, são números impressionantes sob qualquer ponto de vista. A comparação das informações captadas pela PNAD junto aos domicílios entre 2004 e 2006 permite algumas conclusões que decorrem da análise empreendida ao longo deste texto.

A primeira é que, do ponto de vista da informação captada pela PNAD, o número de domicílios beneficiados pelos novos programas unificados sob o BF não se ampliou significativamente entre 2004 e 2006. Houve um aumento líquido relativamente modesto de 337 mil domicílios atendidos a mais. O que ocorreu de fundamental no período em questão foram iniciativas de racionalização e unificação do sistema, que vinha se expandindo de forma desordenada, com muita superposição - 1,5 benefícios por domicílio em 2004 -, regras específicas diferenciadas e praticamente nenhum controle. A unificação da gestão e do controle do BF esteve associada ao uso sistemático do Cadastro Único e à sua atualização como atividade permanente do programa. 
A segunda conclusão refere-se às evidências sobre a focalização. No intervalo de dois anos, aumentou o percentual de domicílios com RDPC acima do limite arbitrário de $\mathrm{R} \$ 130$ após o recebimento da transferência. Este percentual chegou, em 2006, a 48\% dos beneficiários do BF, enquanto, concomitantemente, reduziu-se tanto o número - de 1,3 milhão para 1,0 milhão, como a participação percentual de 17,2\% para 12,6\% - dos domicílios atendidos com as rendas mais baixas - inferiores a R $\$ 50 / 60^{29}$ per capita. Esta evolução se explica em parte pelo crescimento da renda no período, particularmente na base da distribuição, assim como pela alteração dos limites de valor para qualificação como beneficiário no programa. Certamente, estes mesmos fatores contribuíram para a redução importante de 1,5 milhão, entre 2004 e 2006, do número de domicílios elegíveis, mas ainda não atendidos pelo $\mathrm{BF}$, já que nem a expansão do programa nem mudanças na focalização podem explicar, por si só, este resultado.

Como ainda permaneciam, em 2006, 3,4 milhões de domicílios elegíveis a descoberto, sendo 1 milhão deles com renda domiciliar per capita inferior a $\mathrm{R} \$ 60$, foram feitas simulações do impacto sobre a pobreza da imputação do benefício do BF a estes domicílios. Simulou-se também o efeito potencial do novo benefício de R\$ 30 aos jovens de 16 e 17 anos, criado em 2008. Complementarmente, foi feita uma simulação relativa ao efeito da atribuição do novo benefício aos jovens para os domicílios a descoberto após a imputação do benefício básico do BF.

Atender a todos os domicílios elegíveis, mas ainda a descoberto pelo BF, permite obter maior redução dos indicadores de pobreza, embora a um custo total bem mais elevado que aquele associado ao novo benefício aos jovens nos domicílios já atendidos. No entanto, ao comparar o custo unitário sobre o indicador de hiato quadrático, que reflete melhoria em todos os aspectos da pobreza - número de pobres, nível de renda e distribuição da renda - é inequívoca a vantagem de atender prioritariamente aos elegíveis, ao invés de introduzir benefícios adicionais que elevem a renda dos domicílios já beneficiários. Quanto mais bem focalizados estiverem os benefícios na base da distribuição e quanto maior o número de domić́lios atendidos na faixa de renda mais baixa, maior o retorno obtido em termos de redução da pobreza para cada real adicional de dispêndio com o programa.

Assim, em termos estritamente da transferência de renda, o desafio principal do BF é o de atender a totalidade da população elegível, objetivo que vinha sendo enfrentado com sucesso na conjuntura econômica favorável que tivemos no país desde 2004, caracterizada por ocupação e rendimentos crescentes,

(29) O limite superior da faixa mais baixa para elegibilidade ao BF passou de R\$50 em 2004 para R\$ 60 em 2006. 
beneficiando particularmente pessoas e domicílios na base da distribuição de rendimentos. ${ }^{30} \mathrm{Em}$ um ambiente econômico menos favorável, este desafio tende a tornar-se mais difícil de enfrentar pelo aumento da clientela potencial combinado à reconhecida dificuldade de os programas sociais chegarem aos mais pobres entre os pobres.

\section{Referências bibliográficas}

BARROS, R. P.; CARVALHO, M.; FRANCO, S.; MENDONÇA, R. Macrodeterminantes da queda na desigualdade no Brasil. Rio de Janeiro: Ipea, 2006.

CEDEPLAR, Projeto de Avaliação de Impacto do Bolsa-Familia. Belo Horizonte, 2006.

FOSTER, J.; GREER, J.; THORBECKE, E. A class of decomposable poverty measures. Econometrica, v. 52, p. 761-767, 1984.

IBGE. Pesquisa Nacional por Amostra de Domicílios - 2004 e 2006 (microdados).

LAVINAS, L.; ROCHA, S.; VARSANO, R. Programas de Garantia de Renda MinimaUma orientação para os municípios. Rio de Janeiro: Friedrich Ebert Stiftung (ILDES)/ Fundação Ford, 1998. 88p.

HOFFMANN, Rodolfo. O limite entre os relativamente pobres e os relativamente ricos em 2004. Campinas: Unicamp, 2005.

MDS. Análise comparativa de Programas de Proteção Social, 1995-2003. Brasília, 2004.

ROCHA, Sonia. Minimum income programs - How do they apply to Brazilian metropolitan nuclei? [s.n.t.], 1999. Mimeografado.

. Pobreza no Brasil - O que há de novo no limiar do século XXI. Economia, v. 2, n. 1, jul. 2001.

ROCHA, Sonia. O mercado de trabalho e a inserção produtiva dos jovens. In: SEMINÁRIO DE ANÁLISE DOS RESULTADOS DA PESQUISA NACIONAL POR AMOSTRA DE DOMICÍlIOS, 2, CGEE / MDS, Brasília, mar. 2007.

- Transferências de renda federais: focalização e impactos sobre pobreza e desigualdade. Revista de Economia Contemporânea, v. 9, n. 1, p. 67-95, jan./abr. 2008a.

- Transferência de renda focalizadas nos pobres - O BPC versus o Bolsa Família. Sinais Sociais, v. 3, n. 8, p. 150-186, set./dez. 2008 b.

; GARCIA, E.. O Programa de Bolsa Escola Federal - Uma avaliação do desenho e da operacionalização no período 1998-2000. Geneva: OIT, jul. 2001.

(30) No segundo semestre de 2008, havia, no Cadastro Único do MDS, cerca de 2 milhões de domicílios elegíveis e não beneficiários, mas o governo se mantinha fiel ao compromisso de limitar o atendimento do Bolsa Família ao contingente de 11 milhões de domicílios. Como mostram as decisões quanto ao aumento do valor do benefício (em agosto de 2007 e em julho de 2008), assim como quanto à criação do benefício para os jovens de 16 e 17 anos, em março de 2008, não se trata de uma restrição estritamente orçamentária. 
SCWARTZMAN, Simon. Education-oriented social programs in Brazil: the impact of Bolsa Escola. Global Conference on Education Research. Developing Countries, 2005.

SOARES, F. V.; SOARES, S.; MEDEIROS; M., OSÓRIO; R. Programas de Transferências de Renda no Brasil: impactos sobre a desigualdade e a pobreza. Brasília: IPEA, 2006.

SOARES, Sergei. Distribuição de renda no Brasil de 1976 a 2004 com ênfase no período entre 2001 e 2004. Brasília: Ipea, 2006. 27p. (Texto para Discussão, n. 1166). 


\section{Anexo 1}

Valor das Linhas de Pobreza

(R\$ per capita/mês em setembro de 2006)

\begin{tabular}{|c|c|}
\hline Regiões e Estratos & Linha de Pobreza \\
\hline \multicolumn{2}{|l|}{ Norte } \\
\hline Belém & 155,04 \\
\hline Urbano & 135,15 \\
\hline Rural & 67,80 \\
\hline \multicolumn{2}{|l|}{ Nordeste } \\
\hline Fortaleza & 150,79 \\
\hline Recife & 222,75 \\
\hline Salvador & 195,44 \\
\hline Urbano & 133,82 \\
\hline Rural & 80,72 \\
\hline \multicolumn{2}{|c|}{ Minas Gerais/Espírito Santo } \\
\hline Belo Horizonte & 195,82 \\
\hline Urbano & 131,65 \\
\hline Rural & 77,94 \\
\hline \multicolumn{2}{|l|}{ Rio de Janeiro } \\
\hline Metrópole & 227,37 \\
\hline Urbano & 141,47 \\
\hline Rural & 103,27 \\
\hline \multicolumn{2}{|l|}{ São Paulo } \\
\hline Metrópole & 266,15 \\
\hline Urbano & 170,07 \\
\hline Rural & 106,99 \\
\hline \multicolumn{2}{|l|}{ Sul } \\
\hline Curitiba & 175,73 \\
\hline P.Alegre & 141,57 \\
\hline Urbano & 119,14 \\
\hline Rural & 80,32 \\
\hline \multicolumn{2}{|l|}{ Centro-Oeste } \\
\hline Brasília & 265,42 \\
\hline Goiânia & 243,30 \\
\hline Urbano & 185,25 \\
\hline Rural & 106,39 \\
\hline
\end{tabular}

Fonte: Rocha. 


\section{Anexo 2}

Comparação de resultados das três Simulações

Tabela 8A

Simulações de impacto da imputação do benefício aos jovens de 16 e 17 anos Brasil, 2006

\begin{tabular}{c|c|c|c|c}
\hline Cenários* & $\begin{array}{c}\text { Número } \\
\text { de Pobres }\end{array}$ & $\begin{array}{c}\text { Proporção } \\
\text { de Pobres }\end{array}$ & Hiato de Renda & Hiato Quadrático \\
\hline Original & 46.932 .010 & 0,25693 & 0,38865 & 0,05553 \\
\hline Simulação A & 46.477 .058 & 0,25444 & 0,36677 & 0,04865 \\
\hline Diferença & -454.952 & $-0,97$ & $-5,63$ & $-12,38$ \\
\hline$\Delta \% *$ & & 0,25609 & 0,38510 & 0,05450 \\
\hline Simulação B & 46.777 .330 & $-0,33$ & $-0,91$ & $-1,84$ \\
\hline Diferença & -154.680 & 0,25384 & 0,36493 & 0,04815 \\
\hline$\Delta \% *$ & & $-1,21$ & $-6,10$ & $-13,27$ \\
\hline Simulação C & 46.366 .006 & -566.004 & &
\end{tabular}

* Diferença ou variação entre cada simulação e o cenário original.

Fonte: PNAD 2006 (Tabulações especiais).

Tabela 9A

Custo simulado da redução do número de pobres ( $\mathrm{R} \$$ por indivíduo pobre a menos)

\begin{tabular}{l|c|c|c}
\hline Simulações & $\begin{array}{c}\text { Custo Total } \\
\text { (R\$ mil) }\end{array}$ & $\begin{array}{c}\text { Redução do número } \\
\text { de Pobres }\end{array}$ & Custo Unitário (R\$) \\
\hline Simulação A & 171.359 & 454.952 & 376,65 \\
\hline Simulação B & 30.706 & 154.680 & 198,51 \\
\hline Simulação C & 192.927 & 566.004 & 340,86 \\
\hline
\end{tabular}

Fonte: PNAD 2006 (Tabulações especiais).

Tabela 10A

Custo simulado da redução dos indicadores de hiato da renda

\begin{tabular}{l|c|c|c|c|c}
\hline & & $\begin{array}{c}\text { Hiato de } \\
\text { Renda }\end{array}$ & \multicolumn{3}{|c}{ Hiato Quadrático } \\
\cline { 3 - 6 } Simulações & $\begin{array}{c}\text { Custo Total } \\
\text { (R\$ mil) }\end{array}$ & $\begin{array}{c}\text { Redução } \\
\text { total (\%) }\end{array}$ & $\begin{array}{c}\text { Custo por ponto } \\
\text { percentual } \\
\text { reduzido } \\
\text { (R\$ mil) }\end{array}$ & $\begin{array}{c}\text { Redução } \\
\text { total (\%) }\end{array}$ & $\begin{array}{c}\text { Custo por ponto } \\
\text { percentual } \\
\text { reduzido } \\
\text { (R\$ mil) }\end{array}$ \\
\hline Simulação A & 171.359 & 5,63 & 30.448 & 12,38 & 13.839 \\
\hline Simulação B & 30.706 & 0,91 & 33.682 & 1,84 & 16.699 \\
\hline Simulação C & 192.927 & 6,10 & 31.615 & 13,27 & 14.534 \\
\hline
\end{tabular}

Fonte: PNAD 2006 (Tabulações especiais). 